\title{
Intoxicados e silenciados: contra o que se luta?
}

\author{
Poisoned and silenced: fight against what?
}

Envenenadas y silenciadas: luchar contra qué?

Larissa Carvalho de OLIVEIRA ${ }^{1}$

\section{RESUMO}

Este trabalho trata da pulverização de agrotóxico, por meio de avião agrícola, sobre a Escola Municipal Rural São José do Pontal, localizada no Assentamento Pontal do Buriti, município de Rio Verde-GO, ocorrido na manhã de uma sexta-feira, no início do mês de maio de 2013. A grave situação analisada reflete a estrutura de um modelo de produção agrícola hegemônico e suicida, que predomina na região e é imposto à zona rural. Além disso, há morte real das vozes que ousam lutar na busca de tratamento de saúde adequado para as pessoas atingidas, pois são vozes de membros da comunidade do próprio assentamento, que não têm vez na mídia e são intermediados por parlamentares ou pelo Ministério Público. A mídia silencia sobre a responsabilização de quem deu causa à pulverização aérea de agrotóxico, que intoxicou pessoas e contaminou o ambiente escolar e da comunidade do assentamento. Limitou-se a noticiar que houve prisões e solturas, mediante pagamento de fiança. Porém, o debate tímido e insuficiente sobre os problemas trazidos pelo agronegócio foi iniciado com alguns representantes do povo. Nesse sentido, esse trabalho tem por objetivo identificar o que foi relatado na mídia sobre o caso, estabelecer um registro mnemônico sobre as tentativas de ações para providenciar o tratamento de saúde das vítimas, no período entre 3 de maio de 2013 e 29 de outubro do mesmo ano, e iniciar a reflexão sobre o fato a partir de estudo bibliográfico.

Palavras-chave: intoxicação; saúde coletiva; venenos.

\section{ABSTRACT}

This paper deals with the spraying of pesticides through agricultural aircraft on the rural School São José do Pontal, located in the settlement Pontal do Buriti, Rio Verde-GO. It occurred on the morning of a Friday, at the beginning of month of May 2013. This severe situation reflects the structure of a hegemonic and suicidal model of agricultural production, that is prevalent in the region and is imposed on the countryside. Moreover, there is real death of voices who dare fighting

1 Estudante do nono período de graduação em Direito na Universidade Federal de Goiás, Regional Jataí. Bolsista do Núcleo de Estudos, Pesquisa e Extensão em Agroecologia e Agricultura Familiar (NEAF). Este trabalho foi orientado pela professora Ms. Helga Maria Martins de Paula. Endereço de estudo: Universidade Federal de Goiás - Regional Jataí, Campus Jatobá, Rodovia BR-364, KM 192, Setor Parque Industrial, n. 3.800, Central de Aulas 1 - Sala 18, Caixa Postal 03, CEP: 75801-615, Jataí - GO. E-mail: larissa.lco@gmail.com. 
against it and seek for appropriate health treatment for the affected people. They are voices of members of the settlement community, which has no space in the media and, therefore, needs to be mediated by legislators or by the Ministério Público. The media is silent as to the accountability of those who gave cause to the aerial spraying of pesticides that poisoned people and contaminated the school and community environment of the settlement. It merely reported that there were arrests and releases, on bail. However, the timid and insufficient discussion on the problems brought by agribusiness started with some representatives of the people. Thus, this study aims to identify what was reported in the media about the case, establish a mnemonic record of attempts to arrange actions to treat health of victims, between 3 May 2013 and 29 October same year, and to begin reflecting about the fact through bibliographic study.

Keywords: poisoning; public health; poisons.

\section{RESUMEN}

Este artículo trata de la pulverización de pesticidas por medio de aviones agrícolas, arriba de la Escuela Municipal Rural São José do Pontal, ubicada en el Asentamiento Pontal do Buriti, Rio Verde-GO, que se produjo en la mañana de un viernes, en el comienzo de mes de mayo de 2013. La grave situación analizada refleja la estructura de un modelo hegemónico y suicida de producción agrícola, que predomina en la región y se impone en el campo. Por otra parte, hay muerte real de las voces que se atreven a luchar en la búsqueda de tratamiento de salud adecuado para las personas afectadas. Son las voces de los miembros de la propia comunidad de Asentamiento, que no tiene epacio en los medios y necesitan estar mediadas por los legisladores o por el Ministério Público. Los medios de comunicación no se refieren a la responsabilidad de los que dieron causa a la fumigación aérea de plaguicidas que envenenó las personas y contaminó el ambiente escolar y la comunidad del asentamiento. Se limitan a informar que hubo arrestos y liberaciones, en libertad bajo fianza. Sin embargo, la discusión tímida e insuficiente de los problemas provocados por la agroindustria comenzó con algunos representantes del pueblo. Así, este estudio tiene como objetivo identificar lo que se informó en los medios de comunicación sobre el caso, establecer un registro mnemónico de intentos para organizar acciones para el tratamiento de la salud de las víctimas, entre el 3 de mayo de 2013 y 29 de octubre mismo año, y comenzar la reflexión sobre el hecho por medio de estudio bibliográfico.

Palabras clave: envenenamiento; salud pública; venenos.

\section{INTRODUÇÃO}

A pulverização de veneno sobre estudantes, professores e outros funcionários de uma Escola rural em um município do interior do estado de Goiás e as consequências dessa grave situação são abordadas neste trabalho. A análise possui o recorte temporal da data do fato, 3 de maio de 2013, até considerações sobre a audiência pública realizada no município em que se localiza a escola 
rural, realizada em 29 de outubro de 2013.

A hipótese do estudo abrange a questão da invisibilidade proposital daqueles que lutam para ter assegurado seu direito à saúde. Não "são" invisíveis, mas "se tornam", por determinação e comodidade de quem está no poder. Além disso, algumas providências mínimas e insuficientes para o tratamento de saúde dos atingidos somente ocorrem por conta da pressão política exercida pelos protagonistas do caso, as vítimas de intoxicação e seus familiares.

Nesse sentido, objetiva-se compreender e minimamente buscar contribuir para que situações como a apresentada neste trabalho não se repitam nem tão perto nem tão longe de onde se atua acadêmica ou profissionalmente. Objetiva-se também reconhecer os determinantes da realidade opressora do contexto estudado e vislumbrar maneiras viáveis para a sua superação, tendo como base a teoria crítica, pois "a realidade, qualquer que seja o modo como é concebida, é considerada pela teoria crítica como um campo de possibilidades e a tarefa da teoria consiste precisamente em definir e avaliar a natureza e o âmbito das alternativas ao que está empiricamente dado."1

Este estudo possui, entre suas motivações, a clareza de "[...] que defender la vida es urgente donde la aceleración produtiva y el uso destructor de tecnología, basados en mecanismos de explotación de la naturaleza y del ser humano, arrastan a las sociedades a un modelo suicida de desarrollo."2

A metodologia adotada baseia-se no levantamento de cunho investigativo de jornais, revistas e reportagens televisivas que trataram do caso e são veiculados no município em que o assentamento se localiza, Rio Verde-GO. O levantamento das informações parte do critério de analisar o material midiático disponibilizado aos habitantes da própria localidade, no período entre maio e outubro de 2013. Além disso, o método dedutivo de estudo - que considera premissas gerais para incidir em determinantes concretas ${ }^{3}$-, contribui especialmente para a revisão bibliográfica, na terceira parte do trabalho, "Reflexões a partir do caso", pautando as considerações que seguem o relato sobre o caso em si.

Inicialmente, aborda-se o caso da pulverização aérea de agrotóxico sobre estudantes e funcionários da Escola Municipal Rural São José do Pontal, localizada no Assentamento Pontal do Buriti, município de Rio Verde-GO. Nessa parte do desenvolvimento do trabalho, as fontes jornalísticas servem para a comunicação das matérias veiculadas entre si, dispostas em ordem cronológica.

Nesse sentido, são destacados elementos identificadores do contexto analisado, com localização, sintomas iniciais de intoxicação, providências tomadas no dia do fato, órgãos envolvidos, responsabilização dos causadores dos danos e atitudes de autoridades políticas.

Na sequência e em tom conclusivo, são relacionados aspectos sobre o contexto em que ocorreu a pulverização do agrotóxico e a política desenvolvimentista que pressiona para o silenciamento dos atingidos. Alguns elementos semelhantes ao caso, ocorridos na região da Chapada do Apodi, estado ISSN 1982-8829 Tempus, actas de saúde colet, Brasília, 8(2), 109-132, jun, 2014// 
do Ceará, também foram considerados, a fim de se expressar sobre os malefícios do agronegócio.

\section{Pulverização aérea de agrotóxico sobre uma escola rural}

Alguns meios de comunicação de massa divulgaram informações acerca do caso da pulverização aérea de agrotóxicos sobre a Escola Municipal Rural São José do Pontal (criada em 1996 pela Lei Municipal de Rio Verde-GO n. 3.352/964), localizada no Assentamento Pontal do Buriti, município de Rio Verde-GO. A reportagem sobre o envenenamento das pessoas na escola, presente na revista impressa Galileu, de setembro de 2013, aborda o caso relacionando-o a posicionamentos de estudiosos da questão do uso de agrotóxicos e a casos semelhantes de intoxicação de pessoas, explicitando a gravidade do ocorrido no assentamento, na medida em que existem comprometimentos à saúde das pessoas atingidas e ao meio ambiente como um todo.

A mídia televisiva veiculou determinadas notícias sobre o caso em análise, em jornais, mas deteve-se a repassar informações - mesmo sem fontes seguras de dados - na data do fato e em alguns dias que se seguiram, optando pelo posterior silêncio, a despeito da gravidade e não cessação das consequências da exposição ao agrotóxico.

O jornal impresso de circulação regional - em relação ao município de Rio Verde-GO, em que se localiza o assentamento -, denominado Tribuna do Sudoeste, é distribuído semanalmente. No período compreendido entre 28 de abril de 2013 e 18 de janeiro de 2014 apresentou sete edições com reportagens relacionadas ao caso da pulverização aérea sobre a escola rural.

Além disso, o conteúdo da revista Galileu aborda o caso por meio da perspectiva de crianças e adolescentes, desde o momento em que começou a pulverização de agrotóxicos sobre a escola (as indicações "escola" e "escola rural" referem-se à Escola Municipal Rural São José do Pontal, que foi pulverizada por agrotóxicos em 3 de maio de 2013 e se localiza no Assentamento Pontal do Buriti, município de Rio Verde-GO). Alguns alunos estavam no parquinho, na quadra de esportes ou nos corredores, outros lanchavam, pois era hora do recreio, na manhã do dia 3 de maio de 2013.

O mesmo texto da revista considerada indica que, na manhã em que ocorreu a pulverização, "o sol era forte, como sempre, até uma estranha garoa cair sobre o local." A substância química derramada sobre as pessoas que estavam na escola era agrotóxico, mais precisamente, um inseticida denominado Engeo Pleno, produzido pela transnacional Syngenta e composto por tiametoxam $(14,1 \%)$; lambda-cialotrina $(10,6 \%)$ e ingredientes inertes $(87 \%)^{6}$. A reportagem da revista, do mês de setembro de 2013, apresenta uma análise ampla que escancara o vínculo entre incidências de câncer, suicídios, condições humanas depressivas e uso de agrotóxicos, a partir de estudos de pesquisadores da Fundação Oswaldo Cruz (Fiocruz), do Instituto Nacional do Câncer, da Universidade de Brasília e da Campanha Permanente Contra os Agrotóxicos e Pela Vida.

O tom dessa reportagem da Galileu é de denúncia quanto à ausência de controle adequado 
para o emprego de agrotóxicos nas plantações, especialmente de alimentos, e quanto à falta de acompanhamento das pessoas intoxicadas. Esse aspecto reforça o despreparo das equipes de saúde pública para reconhecerem e tratarem pessoas com sintomas persistentes e que se agravam com o decorrer do tempo, assim como perceptível nesse caso de intoxicações de diversos estudantes e funcionários da escola. Nesse sentido, o autor da matéria esclarece que a equipe da revista dialogou com pessoas atingidas pela pulverização, em Rio Verde-GO. A partir dos diálogos, o texto expressa que, no dia do fato, algumas turmas ainda estavam em salas de aula, quando o avião pulverizador começou a sobrevoar a escola.

O gestor da escola rural estava lanchando no momento do fato e seus braços foram visivelmente pulverizados. Em seguida, assim que professores e demais funcionários da escola perceberam a gravidade da situação, os alunos foram conduzidos para a sala da secretaria. Alguns funcionários e alunas, especialmente do Ensino Médio, ajudaram a lavar as crianças, que são alunas e alunos do Ensino Fundamental, porque estavam desesperados. Os sintomas iniciais predominantes, por conta da intoxicação, eram: falta de ar, coceiras, desmaios e vômitos.

Nessa mesma abordagem acerca dos elementos caracterizadores do dia do fato, a reportagem televisiva desse dia, veiculada no jornal regional de primeira edição da TV Anhanguera, afiliada da Rede Globo, indicou que o denominado "acidente" havia ocorrido próximo à cidade de ParaúnaGO, em uma Escola do "Assentamento Pontal", em que cerca de 40 alunos foram intoxicados?. Contudo, o nome correto do local é Projeto de Assentamento Pontal do Buriti, conforme página eletrônica da Superintendência Regional do Incra em Goiás: http://incragoias.wordpress.

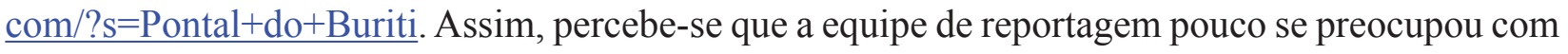
a procedência das informações obtidas, pois além da imprecisão em alguns aspectos (seria mais preciso indicar que o assentamento em que se localiza a escola atingida fica no município de Rio Verde-GO), ainda repassou informações errôneas (o nome do assentamento está errado).

Na mesma edição do jornal televisivo, de 3 de maio de 2013, noticiou-se sobre a comunicação telefônica realizada com o Comandante do Corpo de Bombeiros Militar de Rio Verde, a fim de se obter maiores esclarecimentos acerca do caso. A partir da conversa com o referido comandante, a apresentadora do jornal informou que 122 estudantes estavam na escola e foram vítimas da pulverização, naquela manhã de 3 de maio. Foi identificado o nome do inseticida, Engeo Pleno, usado na pulverização que os vitimou e que, segundo o comandante, trata-se de agrotóxico de baixa toxicidade. Nesse mesmo enfoque, em outra oportunidade, o secretário de comunicação da Prefeitura Municipal de Rio Verde fez considerações sobre a baixa classificação toxicológica do produto empregado na pulverização aérea, no jornal impresso Tribuna o Sudoeste ${ }^{8}$.

Todavia, diferentemente das considerações do comandante do Corpo de Bombeiros e do secretário de comunicação, de acordo com orientações das páginas eletrônicas da Agência Goiana de Defesa Agropecuária (AGRODEFESA), item Agrotóxicos cadastrados em Goiás ${ }^{9}$, e da Agência Nacional de Vigilância Sanitária (Anvisa), na seção Critérios para a classificação toxicológica ${ }^{10}$, o 
agrotóxico Engeo Pleno possui classificação de medianamente tóxico, não é pouco tóxico, menos ainda possui "baixa toxicidade", conforme se indicou na reportagem.

Ainda de acordo com a reportagem televisiva do dia 3 de maio de 2013, alguns profissionais do Corpo de Bombeiros se deslocaram até o assentamento para prestar assistência aos atingidos. Também envolveram-se nesse auxílio a Secretaria Municipal de Saúde e o Serviço de Atendimento Móvel de Urgência (SAMU). No entanto, a apresentadora do jornal não tinha confirmação se o agrotóxico que caiu sobre a escola fora pulverizado diretamente acima dela ou se fora levado pelo vento ${ }^{11}$.

Por outro lado, quanto ao estado de saúde de alguns atingidos pelo agrotóxico, havia pessoas com vômitos, coceiras e alguns lacrimejavam. Por conta desses sintomas característicos de intoxicação - de alunos e professores -, as vítimas foram atendidas inicialmente no Hospital Municipal de Montividiu-GO, pois é o mais próximo da escola, tendo sido levadas por um ônibus escolar.

Contudo, diferentemente da quantidade de alunos atingidos que foi anunciada na primeira edição do jornal da TV Anhanguera, a segunda edição deste jornal do dia do fato (transmitido no início da noite), apresentou o número de 29 vítimas da pulverização aérea de agrotóxicos. Foram exibidas imagens da escola, com familiares à espera de notícias dos alunos do período matutino, pois alguns já estavam hospitalizados ${ }^{12}$. Explicitou-se, nessa reportagem do jornal televisivo, que a informação sobre o momento da pulverização - era hora do recreio das turmas que estudam de manhã - e outros dados veiculados tiveram como fonte as consultas anteriores com alguns pais de alunos presentes na escola, logo após a pulverização.

Em relação ao motivo da pulverização de agrotóxico que resultou na intoxicação da comunidade escolar do Assentamento Pontal do Buriti, explicitou-se que o alvo inicial do agrotóxico era a plantação de milho, localizada próxima à Escola Municipal Rural São José do Pontal, situada no assentamento rural, a $130 \mathrm{~km}$ da zona urbana de Rio Verde, que possui uma média de 300 alunos matriculados.

Em diversa perspectiva, afirmou-se, na segunda edição do jornal da TV Anhanguera, que os alunos estavam na quadra de esportes, na qual não há cobertura, como se todos estivessem apenas naquele espaço, na manhã de 3 de maio de 2013. Essa informação foi mais restrita quanto à localização dos alunos no momento da pulverização do que acima explicitado acerca da reportagem da revista Galileu.

Novamente preocupada com as estatísticas, a reportagem apresentou os números de 37 vítimas, sendo 29 crianças e 8 adultos. O diretor da escola e alguns professores estavam entre os adultos ${ }^{13}$. Os mesmos dados foram apresentados na revista Galileu: “Ao todo, 29 crianças e 8 professores foram levados até o hospital da cidade de Montividiu, a 57 quilômetros, a mais próxima dali."14 Porém, não foram todas as pessoas presentes na escola que tiveram sintomas imediatamente após 
a pulverização.

Nesse viés, a primeira reportagem do jornal impresso Tribuna do Sudoeste que aborda o caso possui indicação curta e textual na capa da edição remetendo o leitor à matéria da página 4 . A nota de chamada à leitura estabelece-se a partir da indicação "Estudantes levam banho de agrotóxico"15 e informa acerca da hospitalização de alunos e funcionários da escola rural, que haviam sido intoxicados em decorrência de uma pulverização aérea destinada (inicialmente) à plantação de milho.

A reportagem da Tribuna do Sudoeste não precisa o número de pessoas intoxicadas, mas em termos aproximativos pontua a quantidade de 115 pessoas, do turno matutino. Destas, 35 com sintomas fortes de intoxicação foram conduzidas ao Hospital Municipal da cidade de MontividiuGO, com o apoio do SAMU. Além da data e momento da pulverização aérea - aspectos que coincidem com os da reportagem da revista Galileu, acima descritos -, o primeiro texto do Jornal Tribuna do Sudoeste, relativo ao fato, indica que os sintomas iniciais de algumas crianças abrangiam cefaleias, enjoos, dificuldades de respiração e coceiras pelo corpo ${ }^{16}$.

Destacou-se na reportagem televisiva da TV Anhanguera, por meio do jornal da data de 6 de maio de 2013, que os responsáveis pelos alunos atingidos foram avisados sobre a pulverização, por funcionários da escola, no mesmo dia do fato. Muitos pais demonstraram sentimento de revolta com a situação, especialmente pela obviedade de os alunos serem visíveis para o piloto que realizava a pulverização do agrotóxico ${ }^{17}$. Afinal, estavam no recreio e a aeronave sobrevoou muito perto do prédio da escola.

Com enfoque diverso, a primeira reportagem do jornal impresso Tribuna do Sudoeste relata que depois de receberem atendimentos médicos mínimos no Hospital Municipal de MontividiuGO, quinze estudantes foram encaminhados para hospitais de Rio Verde-GO, alguns para a Unidade de Pronto Atendimento (UPA) e outros para o Hospital Municipal dessa cidade. Os encaminhamentos tiveram como motivo o agravamento das condições de saúde especialmente dos alunos estudantes ${ }^{18}$. Contudo, nessa mesma reportagem, segundo o gestor da escola, quando entrevistado, os esclarecimentos médicos, no dia do fato, foram no sentido de afirmar pela ausência de gravidade nos sintomas das pessoas atingidas e que as intoxicações não perdurariam. A despeito disso, orientaram alguns pais para se atentarem à saúde dos filhos, porque poderiam desenvolver reações alérgicas.

Todavia, a empresa responsável pela pulverização comunicou-se com a imprensa negando ter despejado agrotóxico sobre a escola. Apesar disso, no mesmo dia do fato, o piloto do avião, o proprietário e um técnico da empresa foram presos, por ordem emitida pelo delegado da cidade de Rio Verde-GO, por suspeita de crime ambiental e de violação das normas legais quanto ao uso de agrotóxicos ${ }^{19}$. 
No Jornal Tribuna do Sudoeste, o gerente dessa empresa de aviação agrícola chegou a afirmar que o inseticida aplicado na plantação de milho não recaiu sobre a escola ${ }^{20}$. No entanto, esse apontamento contraria as imagens gravadas em um vídeo curto feito por um dos alunos da escola rural, com foco no avião pulverizador, a partir da quadra de esportes da escola, no momento em que ocorria a pulverização aérea do agrotóxico ${ }^{21}$.

Ainda na reportagem inicial sobre o fato, no jornal impresso Tribuna do Sudoeste, verifica-se o posicionamento da Prefeitura Municipal de Rio Verde, por meio do secretário de Comunicação. A Administração Pública Municipal considerou serem insuficientes os dados sobre o caso para justificar tomadas de providências pelos órgãos públicos (leia-se: situações que maculem a imagem do agronegócio na cidade não interessam a determinados políticos com cargos públicos). Esse secretário negou a gravidade do caso, defendendo ser rotineiro o procedimento de pulverização de agrotóxicos, inclusive no entorno de escolas. No entanto, destacou que as empresas que pulverizam costumam informar antecipadamente à escola localizada perto de plantações - o que não ocorreu no caso -, sobre a prática, a fim de que os alunos não tenham aulas enquanto ocorre o procedimento. Todavia, mesmo que tal informe tivesse sido feito, é possível considerar que a contaminação do espaço escolar ocorreria de idêntica forma, inclusive com comprometimento da qualidade da água e poluição com substância química e tóxica do solo e de toda a estrutura escolar.

Por outro lado, enquanto ocorriam as prisões dos responsáveis pela pulverização do agrotóxico, a Secretaria Municipal de Saúde de Rio Verde solicitou que as pessoas atingidas permanecessem em observação na Escola Municipal Adelor Quintiliano ${ }^{22}$. Esta informação também foi divulgada no jornal impresso Tribuna do Sudoeste, considerando-se que, apesar da gravidade dos sintomas, os atingidos inicialmente não puderam dormir nos hospitais para acompanhamento médico e foram conduzidos para uma escola pública de Rio Verde ${ }^{23}$. E, para atendimento mais específico das vítimas, ao menos em tese, uma equipe do Centro de Informação Toxicológica de Goiânia-GO dirigiu-se para Rio Verde, no mesmo dia do fato, a fim de contribuir com o início do tratamento médico dos atingidos ${ }^{24}$. Esse Centro de Informação realizou as notificações das pessoas atingidas na mesma data do fato, dia 3 de maio de 2013, contabilizando terem sido noventa e duas as vítimas da pulverização ${ }^{25}$.

No dia 6 de maio de 2013, o jornal da primeira edição da TV Anhanguera ${ }^{26}$ informou sobre a soltura, com pagamento de fiança de aproximadamente $\mathrm{R} \$ 25.000,00$, dos responsáveis pela pulverização do agrotóxico, no fim de semana imediatamente anterior à data da reportagem, mediante decisão judicial. Porém, a mesma informação aparece com data de soltura diferente na segunda edição do jornal Tribuna do Sudoeste, que aborda o caso. Deste modo, informou-se que a soltura se deu no próprio dia 6 de maio de 2013 (segunda-feira) e não no fim de semana ${ }^{27}$. Segundo informações de autoridades da Delegacia de Polícia de Rio Verde-GO, as investigações continuam com base na suspeita de crime ambiental e violação da Lei n. 7.802/89 (que trata sobre o uso de agrotóxicos), cometidos pelas três pessoas, piloto, técnico e proprietário da empresa responsável. 
O procedimento de investigação dos possíveis crimes, de acordo com a reportagem do jornal impresso, fez-se por meio de depoimentos de pessoas presentes no momento da pulverização; orientação de profissionais da Aeronáutica; esclarecimentos técnicos do Instituto Brasileiro de Meio Ambiente e dos Recursos Naturais Renováveis (Ibama) e da AGRODEFESA. Esta agência autuou a empresa responsável pela pulverização, porque "foi infringida a legislação que regulamenta o modo de aplicação do agrotóxico." 28

Por outro lado, no que tange à contaminação da escola, o Corpo de Bombeiros realizou uma limpeza no prédio, na primeira semana após o fato, com apoio de funcionários da empresa de pulverização. Porém, reconheceu-se que "não foi possível garantir que as dependências da escola tenham sido completamente descontaminadas, tendo em vista que os vistoriadores não possuem conhecimentos técnicos nem equipamentos específicos para realizar a mensuração." 29

A reportagem televisiva de 6 de maio de 2013 teve acesso à nota fiscal do agrotóxico usado na pulverização e tornou público tratar-se da substância Engeo Pleno, mas a indicação da cultura para o agrotóxico era de soja - e não milho - e restou evidenciada a proibição de aplicação aérea do produto. Além disso, na data da reportagem, as aulas estavam suspensas aguardando visita e fiscalização de representantes da AGRODEFESA. Somente após a limpeza do prédio, assim como considerado acima, as aulas poderiam ser retomadas ${ }^{30}$.

Na manhã de terça-feira, dia 7 de maio de 2013, noticiou-se ${ }^{31}$ a autuação do técnico da empresa pela AGRODEFESA, a qual integra o caso por envolver danos ambientais, sendo aquele funcionário da empresa de aviação responsável pela pulverização do agrotóxico, que prescreveu a indicação do produto. A própria empresa também poderá ser autuada, a depender do curso das investigações, especialmente a partir do conteúdo do plano de voo. Até porque, como explicou um fiscal da AGRODEFESA, a distância mínima entre a aplicação de agrotóxico e a circulação de pessoas é de 500 metros, e a escola se localizava a menos de 15 metros da plantação ${ }^{32}$.

Na mesma data dessa reportagem da TV Anhanguera ( 7 de maio de 2013) e nos dias seguintes da mesma semana, ocorreria oitiva de testemunhas na delegacia de Rio Verde, incluindo os estudantes e professores da escola que nela estavam no dia do fato. O delegado responsável esclareceu sobre o acréscimo dos exames de corpo de delito das vítimas ao inquérito policial e a possibilidade de contribuição técnica de um médico especialista em casos de intoxicação para explicar acerca dos sintomas - entre eles dores de cabeça, irritação na pele e vômito. Quanto aos encaminhamentos da investigação, o delegado considerou a possível visibilidade que o piloto do avião pulverizador teve em relação aos alunos da escola, a partir de visita realizada à escola e também de acordo com a perícia.

Em perspectiva diversa, o anexo à edição do jornal Tribuna do Sudoeste, cuja publicação compreende o período de 12 a 18 de maio de 2013, intitulado "Tribuna Agronegócio", apresenta uma mensagem tímida da sindicância iniciada pela Anvisa e divulgada em audiência pública do dia 
6 de maio na Câmara dos Deputados, a fim de se identificar pessoas responsáveis pela pulverização aérea de agrotóxicos sobre a escola rural ${ }^{33}$.

Em relação à terceira reportagem do jornal impresso em análise, é relatado sobre uma Recomendação por parte do Ministério Público Estadual (MPE) e do Ministério Público Federal (MPF) para o Prefeito Municipal de Rio Verde-GO. A matéria está presente na edição do período de 30 de junho a 6 de julho de 2013. A Recomendação data de 28 de junho de 2013 e, em seu conteúdo, demanda que as pessoas atingidas pelo agrotóxico na escola rural sejam atendidas de modo coerente com a especificidade do caso. O número de vítimas indicado é de noventa e duas, sendo setenta e quatro estudantes e dezoito funcionários da escola ${ }^{34}$. Para essas pessoas atingidas, recomenda-se que a Administração Pública Municipal emita nota técnica orientando acerca dos efeitos da intoxicação e do modo de tratamento médico.

Além disso, outra nota técnica havia de ser feita para "profissionais da saúde do município de Rio Verde informando sobre o fato, e orientando para que sejam observados, nos atendimentos realizados na rede local do Sistema Único de Saúde (SUS), os sintomas agudos, subcrônicos e crônicos decorrentes de eventual intoxicação por agrotóxicos" ${ }^{35}$. Contudo, as indicações da recomendação não se limitaram a tais notas, considerou-se ainda a possibilidade da feitura de prontuário para se monitorar o quadro de saúde dos atingidos e destinação de centro de atendimento médico público especialmente para eles, ou tratamento custeado pela empresa causadora dos danos.

As condições ambientais do prédio em que se localiza a escola - no sentido de estar ou não contaminado - e a qualidade da água consumida no local também constituíram aspectos consagrados na Recomendação elaborada pelos órgãos estadual e federal do Ministério Público estabelecidos na cidade em que se localiza o Assentamento Pontal do Buriti.

Nesse sentido, a questão ambiental é abarcada como uma das ponderações na Recomendação, quanto à Escola Municipal Rural São José do Pontal e a todas as escolas rurais do município, especialmente em relação à "vulnerabilidade sanitária, exposição a agentes químicos em desconformidade com as regras que regem a matéria, condições de potabilidade da água"36. Desse modo, todas essas responsabilidades foram atribuídas à Prefeitura Municipal.

Sob diversa perspectiva, a reportagem do jornal Bom Dia Goiás, da TV Anhanguera, do fim do mês de maio ${ }^{37}$, demonstra a vulnerabilidade da condição de saúde das vítimas do agrotóxico pulverizado, pois algumas destas retornaram para hospitais de Rio Verde, alguns dias ou semanas após o fato, devido à persistência de alguns sintomas da intoxicação. A despeito disso, o médico diretor do hospital público de Rio Verde afirmou estarem com quadro de saúde estável, tendo feito os exames laboratoriais e de imagem. A matéria também comunicou sobre a presença de profissionais da Anvisa no município para diagnosticarem o estado de saúde das vítimas.

Além da equipe da Anvisa, um grupo de profissionais da Secretaria Estadual de Saúde também 
compareceu à Rio Verde. Contudo, a repórter do jornal televisivo, do mesmo jornal Bom Dia Goiás, aponta a inexistência de previsão de retornos para continuidade do tratamento médico dos atingidos ao hospital público da cidade, pois nem tratamento adequado ao caso foi disponibilizado. Os atendimentos têm ocorrido precariamente e na dependência de manifestações sintomáticas do pessoal da escola.

Ainda na exibição do jornal televisivo do fim do mês de maio, uma representante da Anvisa manifestou-se publicamente afirmando desconhecerem de quais sintomas crônicos se trata no caso, já que o agrotóxico pulverizado resultava de uma combinação de substâncias diferentes.

Mas, em junho de 2013, uma equipe de profissionais da Fiocruz esteve na escola do Assentamento Pontal do Buriti, em Rio Verde-GO. Como consequência das suas avaliações, a escola foi interditada até nova limpeza para desintoxicação, a qual ocorreu em julho do mesmo ano. Além disso, médicos integrantes dessa equipe afirmaram acerca da possibilidade de que problemas na saúde de determinados atingidos podem levar vários anos para se manifestarem, por conta do que se denomina de intoxicação crônica, devido à "exposição prolongada e reiterada às substâncias, podendo aparecer até 20 anos depois. Eles incluem problemas graves, como câncer, lesões hepáticas, doenças no sistema nervoso, distúrbios hormonais e malformação fetal." ${ }^{38}$

Em diversa perspectiva, a edição do jornal televisivo da manhã de $1^{\circ}$ de julho de 2013 enfatizou a ação de algumas pessoas que depredaram as instalações da Escola Municipal Rural São José do Pontal, deixando as seis salas de aula desarrumadas, carteiras arremessadas, janelas e portão quebrados ${ }^{39}$.

Os danos causados ao patrimônio da escola seriam custeados pelo Poder Público Municipal e a reparação deveria ocorrer até o final das férias escolares de julho. Trata-se da segunda situação grave na escola com um intervalo temporal muito curto e, com um fato aparentemente intensificador do vínculo: a expressão "protesto veneno" escrita no quadro negro de uma das salas de aula. Porém, até a data da reportagem, os autores dos danos não haviam sido identificados e o gestor da unidade escolar mencionou a presença de policiais civis para o início das investigações no prédio, especialmente a partir de possíveis marcas de impressões digitais.

Além disso, no jornal Tribuna do Sudoeste de agosto de 2013, período entre os dias 18 e 24, observa-se uma nota breve sobre a audiência pública realizada para a discussão acerca da pulverização de agrotóxico. As poucas linhas do texto relativo à audiência constam na segunda página e somente a justifica pela pulverização de agrotóxicos sobre a escola, destacando que a Assembleia Legislativa de Goiás a convocou, por meio da "Comissão de Agricultura, Pecuária, Abastecimento e Desenvolvimento"40.

A edição do jornal impresso Tribuna do Sudoeste do segundo semestre de 2013 (de 29 de setembro a 5 de outubro) evidencia a mobilização de determinados setores e profissionais vinculados ao 
Instituto Federal Goiano de Rio Verde na crítica ao uso de agrotóxicos, por meio do "I Simpósio Goiano sobre Agrotóxicos, Meio Ambiente e Saúde", realizado mediante empenho do Programa de Pós-Graduação em Agroquímica ${ }^{41}$. A motivação para o evento se deve ao caso do mês de maio, com a pulverização de agrotóxicos sobre a escola rural. Nesse evento, houve participação de muitos estudiosos da temática no simpósio, inclusive da gerente-geral de toxicologia da Anvisa, a qual demonstrou preocupação quanto ao papel de autorização de uso de substâncias tóxicas em nosso país. Ela também apontou considerações sobre os equipamentos de proteção individual (EPIs) por serem inadequados, considerando características genéricas humanas, e aspectos climáticos incompatíveis com o uso de EPIs elaborados aos padrões de países do Norte e, de qualquer forma, insuficientes para a proteção do usuário, em relação aos agrotóxicos.

Além disso, a referida gerente-geral de toxicologia, no jornal Tribuna do Sudoeste do segundo semestre de 2013, defende o não uso de agrotóxicos, pois "a saída seria a adoção da agroecologia, como o uso de abelhas para a captura de pragas, assim como de bactérias e demais sistemas alternativos à prática agrícola atual" ${ }^{\prime 2}$.

No mesmo evento ocorrido no Instituto Federal Goiano de Rio Verde, um professor da Universidade Federal de Viçosa também palestrou, denunciando a insustentabilidade do atual sistema de produção agrícola. O professor destacou a opção de transição necessária quanto ao modelo de agricultura, com primazia da questão ecológica e distributiva. O palestrante se posicionou de modo contrário à subordinação de sistema agrícola de um país a determinados produtos, à política imediatista de trato com as plantações - dependentes de insumos químicos -, e à carência de estudos científicos sobre práticas alternativas.

Nessa mesma edição do jornal impresso, na matéria logo abaixo dos comentários sobre o Simpósio, um cientista social, em uma visita à Rio Verde, enfatiza a importância da pauta do meio ambiente na organização social e "critica a falta de consciência por parte dos próprios gestores públicos brasileiros, que muitas vezes apresentam considerações superficiais sobre o meio ambiente." Ele esteve no Assentamento Pontal do Buriti e considerou o caso da "chuva de agrotóxicos" sobre a escola ser "um dos mais graves de todo o país"

A sexta edição - relativamente à abordagem sobre o caso - do jornal impresso em análise divulga a audiência pública que ocorreria (e ocorreu) na Câmara Municipal de Rio Verde, em 29 de outubro, a partir das 9 horas, com a discussão principal sobre "O uso de agrotóxicos na produção agrícola e a vulnerabilidade das populações rurais". A ideia para sua realização partiu de um deputado estadual, durante a audiência que se realizou no Senado Federal em que se debateu sobre a pulverização de agrotóxicos sobre a escola. A expectativa para a realização da audiência em Rio Verde era no sentido de intensa participação das vítimas e familiares e ainda presença de autoridades legislativas na escola pulverizada ${ }^{44}$.

Ainda em relação à audiência pública, a sétima matéria do jornal Tribuna do Sudoeste relativa 
ao caso apresenta destaque em uma foto e na mensagem da capa:

Após seis meses do acidente que envolveu alunos e professores de uma escola rural atingida por agrotóxico lançado por avião de pulverização, a cobrança é por melhoria no atendimento médicos às vítimas. Presidente da Comissão de Direitos Humanos do Senado, Ana Rita Esgário (PT) pretende propor a criação de uma comissão multiprofissional, coordenada pelo Ministério da Saúde. Outra proposta é criar uma comissão temporária no Senado a fim de discutir questões de intoxicação. ${ }^{45}$

A parceria entre as comissões de Direitos Humanos do Senado Federal e da Assembleia Legislativa de Goiás viabilizou a realização da audiência pública do dia 29 de outubro de 2013. O objetivo principal era estabelecer propostas de acompanhamento médico de qualidade às pessoas intoxicadas.

Um legislador da esfera estadual de governo ressaltou, na audiência pública em análise, que são variados os efeitos do contato com a substância tóxica, a depender da pessoa. E, como fator ainda mais prejudicial, o atendimento médico público no âmbito municipal foi insuficiente e não contava com especialistas necessários. O parlamentar também trouxe aos presentes reprodução de parte mínima das reclamações das vítimas, com sintomas de gripes constantes, menstruação precoce, desânimo e problemas psicológicos.

Sob diversa perspectiva, a gerente-geral de toxicologia da Anvisa, nessa oportunidade na Câmara Municipal, advertiu sobre o fato de o tipo de agrotóxico que atingiu as pessoas na escola não tinha autorização para uso aéreo. Além desse aspecto que responsabiliza a empresa, a gerente considerou que o avião pulverizador deveria passar, segundo ela, a uma distância de duzentos e cinquenta metros da escola, caso o agrotóxico pudesse ser pulverizado por meio aéreo. Tal afirmação reflete o desconhecimento da gerente-geral acerca das normas que regem a aplicação aérea de agrotóxicos em nosso país. Afinal, a Instrução Normativa n. 2/2008, do Ministério da Agricultura, Pecuária e Abastecimento, em seu artigo 10, inciso I, alínea "a", exige o respeito a uma distância mínima de quinhentos metros de povoações e de locais onde a água é captada para abastecimento de pessoas ${ }^{46}$.

Quanto ao atendimento das vítimas, destacou-se, na audiência, a raridade de profissionais médicos da área de toxicologia em nosso país, situação que se repete em Rio Verde, enfraquecendo ainda mais o tratamento de saúde das pessoas atingidas pelo agrotóxico. Todavia, para minimizar as deficiências no atendimento às vítimas, o Centro de Informação Toxicológica foi acionado e realizou notificações pertinentes ao caso, assim que os pacientes chegaram a hospitais de Rio Verde, no dia do fato, para orientar médicos e enfermeiros sobre os procedimentos mais adequados em caso de intoxicação, conforme considerado acima.

Ainda durante a audiência pública, relatada no jornal Tribuna do Sudoeste do período entre 3 a 9 de novembro de 2013, um momento de ânimos alterados ocorreu quando um dos vereadores 
rioverdenses, que também é médico e atendeu algumas pessoas por conta da pulverização, indicou ser exagerada a forma de se considerar o caso. Porém, ele foi negado em suas afirmações pela gerente-geral de toxicologia da Anvisa, que destacou sintomas reclamados pelos atingidos muito relacionados ao agrotóxico pulverizado, fato esse que descarta argumentos de defesa da irrelevância do caso $^{47}$.

A participação, na audiência, dos protagonistas da luta travada por vítimas e seus familiares para conseguirem tratamento de saúde digno foi destacada com momentos de comoção e de revolta. A partir das falas é indubitável que os efeitos da intoxicação ainda são presentes, com problemas renais, câimbras, dores de cabeça entre outros sintomas que se distinguem a depender da pessoa que foi atingida. Por conta disso, um dos professores reconheceu a diminuição no desempenho dos alunos nas atividades escolares e o fato de ter se transformado em situação corriqueira a apresentação de atestados médicos, desde a pulverização da escola.

Encerrada a audiência, Senadores, integrantes do Ministério da Saúde, do MPF e da Anvisa dirigiram-se à escola. Na oportunidade, a gerente-geral de toxicologia da Anvisa destacou que situações que envolvem uso de agrotóxicos, danos à saúde humana e ao meio ambiente como o caso do Assentamento Pontal do Buriti têm sido comuns, mas há tentativa de autoridades públicas no sentido de tornar tais casos invisíveis.

\section{Reflexões a partir do caso}

A violência relatada acima, por meio de estudo de matérias de jornais e revista, demonstra uma situação vivenciada por uma comunidade vulnerável econômica, social e politicamente. Estudantes e funcionários de uma escola pública localizada em um assentamento e cercada pelas marcas e raízes do agronegócio foram atingidos por agrotóxicos e sofrem as consequências em uma região do Brasil em que as relações de poder tendem a torná-los (e mantê-los) invisíveis. Até porque, endente-se poder como “[...] qualquer relação social regulada por uma troca desigual. É uma relação social porque a sua persistência reside na capacidade que ela tem de reproduzir desigualdade mais através da troca interna de que por determinação externa." 48

Deste modo, o espaço de estudo e trabalho foi atingido, as condições saúde da comunidade escolar presente naquela manhã de maio foram comprometidas de modo inestimável. Em síntese, o meio ambiente foi envenenado, incluindo qualidade da água, condições do solo e animais locais.

Contudo, apesar dos inegáveis prejuízos humanos e ambientais causados por responsabilidade da empresa de aviação agrícola localizada em Rio Verde e de não existirem profissionais no atendimento de saúde pública local com especialidade em toxicologia, houve esforço da empresa para desmerecer os trabalhos de possíveis indicações de médicos a serem contratados para atenderem as vítimas. 
A possibilidade de custeamento pela empresa da vinda do médico e professor da Universidade Federal do Mato Grosso, Dr. Pignati, para atendimento das vítimas foi rechaçado, sob argumento de este profissional não ter imparcialidade. Representantes da empresa também discordaram da presença da pesquisadora Karen Friedrich, pois ela não atua em atendimentos médicos diários.

No entanto, a presença dos profissionais considerados foi resistida porque se posicionam expressamente contrários ao uso de agrotóxicos. Tal resistência restou evidente na reunião do dia 7 de maio de 2013 - cuja ata está inserida no Procedimento Administrativo do Ministério Público Estadual n. 201300227199 - com a presença de um Promotor de Justiça do Ministério Público Estadual de Goiás, um advogado, o gerente e o engenheiro agrônomo da empresa responsável pela pulverização do agrotóxico sobre a escola rural ${ }^{49}$.

Além disso, a empresa responsável pela pulverização dedica vinte e três páginas com sua participação no desenvolvimento do mencionado Procedimento, para criticar os trabalhos do Dr. Wanderlei Pignati. São considerados alguns conteúdos de endereços eletrônicos, a fim de se ressaltar que este médico não é imparcial. Nesse sentido, também se inseriu um parecer de um professor do departamento de Engenharia, da Universidade Federal de Lavras, da área de Máquinas e Mecanização Agrícola/ Tecnologia da Aplicação, de dezembro de 2012. O parecer reputa como não científica uma dissertação do Programa de Pós-Graduação em Saúde Coletiva, de 2011, orientada pelo professor Dr. Pignati, detalhando alguns possíveis equívocos metodológicos e de fundamentação ${ }^{50}$.

A empresa realizou tal desqualificação e, por outro lado, elaborou lista de indicações de médicos entre os quais alguns poderiam ser por ela contratados para tratamento de saúde das pessoas atingidas. Entre os seis nomes de toxicologistas apresentados pela empresa à Promotoria de Justiça, no âmbito do Procedimento Administrativo mencionado ${ }^{51}$, um era do Dr. Ângelo Trapé, pesquisador da Unicamp-SP. Este mesmo profissional negou a existência de risco no uso de agrotóxicos, considerando serem exageradas críticas ao emprego dessas substâncias químicas em reportagem veiculada na Revista Galileu ${ }^{52}$, de setembro de 2013.

Importa ainda ressaltar que a realidade analisada está inserida em um contexto de agronegócio, enquanto modelo agrícola hegemônico, altamente industrializado e propagandeado como evoluído. O sentido de agronegócio criticado corresponde ao da estruturação atual do capitalismo, em que há domínio dos espaços territoriais por poucos grupos econômicos e no qual algumas empresas determinam, pois se apoderam de recursos materiais para isso, as sementes a serem plantadas, o maquinário e os agrotóxicos usados e toda a cadeia de produção à qual o agricultor fica sujeito. Tal agronegócio tem aspecto de indústria, pautando-se na monocultura e produção de commodities, entre elas o milho. Desse modo, a Syngenta, produtora do agrotóxico Engeo Pleno que vitimou a comunidade do Assentamento Pontal do Buriti, encontra-se entre as maiores empresas transnacionais do modelo de agronegócio apontado ${ }^{53}$. 
No entanto, “[...] a industrialização não é necessariamente o motor do progresso nem a parteira do desenvolvimento. Por um lado, ela assenta numa concepção retrógrada da natureza, incapaz de ver a relação entre a degradação desta e a degradação da sociedade que ela sustenta." ${ }^{54}$ E não existe legitimidade para essa forma de produção de alimentos imposta pelo capitalismo, que obsta a sobrevivência e articulação de grupos sociais vulnerabilizados e gera prejuízos incalculáveis ao meio ambiente.

Nesse sentido, a promessa de desenvolvimento, a partir do fomento ao agronegócio, como panacéia para problemas sociais, especialmente a questão da fome, evidencia-se falaciosa. Até porque,

'Desenvolvimento'é uma ideologia que surge e se expande nas sociedades ocidentais a partir do século XIV, junto com o surgimento e a expansão da classe burguesa. Em sua trajetória na História humana, o slogan do desenvolvimento ganha corpo na Revolução Industrial e é celebrado no século XIX, tendo como pano de fundo o 'progresso' trazido pelo capitalismo [...]. Legitima-se pela promessa de que a expansão da esfera econômica libertaria a humanidade da escassez, da injustiça e do mal-estar ${ }^{55}$.

Entretanto, a injustiça e a desumanidade restam materializadas no cotidiano da comunidade do Assentamento Pontal do Buriti e de tantas outras violentadas para custear o crescimento econômico de poucas empresas do agronegócio. Nesse processo de conflitos socioambientais pela manutenção do sistema capitalista, a terra - enquanto meio de sobrevivência de certas comunidades - recebe a conta das atividades desenvolvimentistas e, em sua escassez de recursos e com a força de trabalhadores, banca os lucros empresariais.

A problemática social intensificado com a pulverização de agrotóxico, além de se tornar uma questão de saúde pública - explicitando a incapacidade do SUS local para atender e tratar pessoas intoxicadas -, publiciza um cenário de luta de classes real ${ }^{56}$, de uma comunidade de trabalhadores e filhos de trabalhadores do campo agredidos pelo empresariado do agronegócio. "Vidas invisíveis para o sistema, mas que a luta a torna existente, presente, resignificada." ${ }^{57}$ Porém, tal conflito/luta pressionou para a realização do I Simpósio Goiano sobre Agrotóxicos, Meio Ambiente e Saúde, das audiências públicas e das demandas jurídicas relacionadas ao caso.

Além disso, as características agrícolas do Sudoeste Goiano, na região do Estado de Goiás em que se localiza o Assentamento Pontal do Buriti, são coincidentes com as características do próprio agronegócio com aspecto industrial conforme considerado acima e refletem a expansão do domínio capitalista, mais precisamente de um processo auto-intitulado revolucionário, que data da metade do século passado. A Revolução Verde foi promovida por países desenvolvidos com o discurso justificativo de aumentar a produção de alimentos e eliminar a questão da fome em países não desenvolvidos. Afigurava-se "como modelo de produção racional, voltado à expansão das agroindústrias, com base na intensiva utilização de sementes híbridas, de insumos industriais 
(fertilizantes e agrotóxicos), mecanização da produção, uso extensivo de tecnologia no plantio $[\ldots] . " 58$

O modelo agrícola agronegócio atende a interesses específicos, de uma classe social específica. Está protegido pelo escudo da legalidade e pela estrutura institucional. E a utilização de agrotóxicos, como um dos pilares do lucro do agronegócio, pauta-se em sistema classificatório questionável e sob a responsabilidade do Ministério da Saúde. "Essa classificação é baseada na Dose Letal 50 (DL 50) que se trata de um indicador de efeito a morte e não de saúde, além do que não diz respeito a efeito crônico, mas sim a efeito agudo." ${ }^{59}$

Nesse sentido, a partir dos elementos apresentados no tópico anterior, acerca do caso da pulverização aérea de agrotóxico sobre estudantes e funcionários de uma escola rural, faz-se possível reconhecer muitos pontos de toque com uma comunidade cearense marcada pela exploração do agronegócio. Este modelo que - especialmente com os empresários da fruticultura no Ceará -, influenciou para "a construção, em 1989, do Perímetro Público de Irrigação Jaguaribe-Apodi, que, agora, passa a contemplar áreas para as empresas agrícolas, diferentemente dos perímetros construídos na década de 1970, destinadas, principalmente, a agricultores familiares. ${ }^{~}{ }^{60}$ A região da Chapada do Apodi se localiza na divisa dos estados do Ceará e do Rio Grande do Norte.

Nessa região do Nordeste brasileiro, assim como ocorreu com a comunidade do Assentamento em RioVerde-GO e em outros municípios brasileiros, os sintomas decorrentes do contato com o agrotóxicos são semelhantes, "principalmente cefaleias, vômitos, náuseas e alergias, além de relatos sobre a morte de animais, de galinhas, pássaros e peixes sempre que a "chuva de venenos" acontece. $" 61$

Tanto na região da escola rural pulverizada por agrotóxico quanto na Chapada do Apodi, cuja produção de frutas se baseia no uso de venenos, importa desvelar o contexto sócio-histórico das comunidades, onde a modernização agrícola é promotora das mais variadas condições de desigualdades, acentuadas pela desintegração da cultura e dos seus modos de vida, impondo um modelo que oculta ou desacredita a possibilidade de produzir com sustentabilidade socioambiental. ${ }^{6}$

Ocultam-se inclusive dados sobre algumas das consequências negativas em relação ao emprego de agrotóxicos, a exemplo dos casos de pessoas intoxicadas, pois “"...] a OMS indica que, para cada caso notificado de intoxicação por agrotóxicos, existem 50 casos não notificados. $"{ }^{63}$

Em suma, reflexões e posicionamentos perante esse aspecto da realidade que diz respeito aos danos imediatos e persistentes à saúde humana e, de maneira mais geral, ao meio ambiente, por conta do uso de agrotóxicos nas plantações, justificam a resistência ao agronegócio, como possibilidade para se buscar a redução das desigualdades sociais. 


\section{CONSIDERAÇÕES FINAIS}

Admitindo-se a orientação da teoria crítica e a partir das realidades consideradas acima, fazse coerente explicitar negação ao modelo agrícola hegemônico, por representar uma forma de produção que sacrifica indiscriminadamente a saúde humana e a vida em suas mais variadas formas.

Por meio do cruzamento das informações coletadas, pode-se apreender uma sequência de pseudo-providências, por parte de autoridades públicas e órgãos oficiais, concomitantemente em que as condições de saúde dos atingidos pela pulverização de agrotóxico são agravadas.

Nesse sentido, buscou-se apontar um resgate histórico dos atos realizados para a compreensão dos desdobramentos a partir de uma situação fatídica. Importa ainda ressaltar que o motivo de não se deixar esquecer o caso, de se retomar escritos velhos e que já não aparecem nas bancas de jornal e revistas, nem nas reportagens televisivas, reside na defesa de que o fato e seu impacto nas vidas envolvidas não sejam arquivados. Espera-se que esses não sejam descartados em lixeiras do silenciamento social e político, ao gosto dos empresários do agronegócio.

A conjuntura política regional tende ao embrutecimento e à negação do ocorrido com a comunidade do Assentamento Pontal do Buriti. Porém, a resistência e a luta contra a hegemonia de um modelo agrícola subsidiam-se na teoria crítica e optam por escancarar essa realidade, não como um fato passado, mas como uma situação que se repete em vários locais do Brasil e precisa ser superada.

Em suma, a revisão de literatura, trazida no tópico anterior, possui cunho reflexivo e respeita o caráter de destaque do relato sobre a intoxicação de uma comunidade escolar. Assim, a análise feita parte do caso, admitindo-se e fomentando-se o protagonismo das vítimas e seus familiares, que se viram impelidos a lutar para que suas vozes não se percam nos desertos verdes da região na qual residem.

\section{REFERÊNCIAS}

1. Santos BS. A crítica da razão indolente: contra o desperdício da experiência. 8. ed. v. 1. São Paulo: Cortez; 2011. p. 23.

2. Breilh J. La codicia agrícola como modelo de La muerte (Prólogo). In: RIGOTTO, Raquel (org.). Agrotóxicos, trabalho e saúde: vulnerabilidade e resistência no contexto da modernização agrícola no Baixo Jaguaribe/CE. Fortaleza: Edições UFC co-edição com a Expressão Popular; 2011. p. 25.

3. Bittar ECB. Metodologia da pesquisa jurídica: teoria e prática da monografia para os cursos de direito. 7. ed. São Paulo: Saraiva; 2009. p. 18. 
4. Rio Verde. Lei n. 3.352, de 25 de junho de 1996. Cria e denomina Escolas que menciona. Arquivos da Secretaria de Educação da Prefeitura Municipal.

5. Mali T. Envenenados. Galileu: Editora Globo; n. 266, p. 46-59, set. 2013. ISSN 1415-9856. p. 48.

6. Engeo pleno. Especificações técnicas. Disponível em: < http://www.servicos.syngenta.com. br/produtos/ProductDetails.aspx?idProduct=2286> . Acesso em: 14 maio 2014.

7. Nascimento E, Zago A. Avião agrícola sobrevoa escola e intoxica dezenas de crianças, em GO. TV Anhanguera - Globo; 03 maio 2013. Disponível em: $<\underline{\text { http://g1.globo.com/goias/noticia/2013/05/aviao- }}$ agricola-sobrevoa-escola-e-intoxica-dezenas-de-criancas-em-go.html>. Acesso em: 12 dez. 2013.

8. Tarcísio T. Avião pulveriza agrotóxico "sobre" alunos em escola. Tribuna do Sudoeste, Rio Verde: Tribuna do Planalto; n. 407, pp. 1 e 4, 5 a 11 de maio de 2013a. p. 4.

9. Agrodefesa. Agrotóxicos cadastrados em Goiás. Disponívelem: $<$ http://www.agrodefesa.go.gov. br/agrotoxicos >. Acesso em: 05 abr. 2014.

10. Anvisa. Critérios para a classificação toxicológica. Disponível em: < $\underline{\text { http://portal. }}$ anvisa.gov.br/wps/portal/anvisa/anvisa/home/agrotoxicotoxicologia/!ut/p/c4/04 SB8K8xLLM9MSSzPy8xBz9CP0os3hnd0cPE3MfAwMDMydnA093Uz8z00B_A3dj M_2CbEdFANFW4Q0!/?1dmy\&urile=wcm\%3 Apath\%3A/anvisa+portal/anvisa/inicio/ agrotoxicos+e+toxicologia/publicacao + agrotoxico+toxicologia/criterios + para $+\mathrm{a}+$ classificacao + to xicologica> . Acesso em: 05 abr. 2014.

11. Nascimento E, Zago A. Avião agrícola sobrevoa escola e intoxica dezenas de crianças, em GO. TV Anhanguera - Globo; 03 maio 2013. Disponível em: $<$ http:/g1.globo.com/goias/noticia/2013/05/aviaoagricola-sobrevoa-escola-e-intoxica-dezenas-de-criancas-em-go.html >.Acesso em: 12 dez. 2013.

12. Tv Anhanguera. Piloto de avião agrícola que intoxicou várias pessoas em escola está preso. Globo; 03 maio 2013a. Disponível em: 〈http://g1.globo.com/goias/noticia/2013/05/piloto-de-aviao-agricola-queintoxicou-varias-pessoas-em-escola-esta-preso.html>. Acesso em: 12 dez. 2013.

13. Tv Anhanguera. Piloto de avião agrícola que intoxicou várias pessoas em escola está preso. Globo; 03 maio 2013a. Disponível em: 〈http://g1.globo.com/goias/noticia/2013/05/piloto-de-aviao-agricola-queintoxicou-varias-pessoas-em-escola-esta-preso.html>. Acesso em: 12 dez. 2013.

14. Mali T. Envenenados. Galileu: Editora Globo; n. 266, p. 46-59, set. 2013. ISSN 1415-9856. p. 49.

15. Tarcísio T. Avião pulveriza agrotóxico "sobre" alunos em escola. Tribuna do Sudoeste, Rio Verde: Tribuna do Planalto; n. 407, pp. 1 e 4, 5 a 11 de maio de 2013a. p. 1. 
16. Tarcísio T. Avião pulveriza agrotóxico "sobre” alunos em escola. Tribuna do Sudoeste, Rio Verde: Tribuna do Planalto; n. 407, pp. 1 e 4, 5 a 11 de maio de 2013a. p. 1.

17. Tv Anhanguera. Piloto de avião agrícola que intoxicou várias pessoas em escola está preso. Globo; 03 maio 2013a. Disponível em: <http:/g1.globo.com/goias/noticia/2013/05/piloto-de-aviao-agricola-queintoxicou-varias-pessoas-em-escola-esta-preso.html>. Acesso em: 12 dez. 2013.

18. Tarcísio T. Avião pulveriza agrotóxico "sobre" alunos em escola. Tribuna do Sudoeste, Rio Verde: Tribuna do Planalto; n. 407, pp. 1 e 4, 5 a 11 de maio de 2013a.

19. Tv Anhanguera. Piloto de avião agrícola que intoxicou várias pessoas em escola está preso. Globo; 03 maio 2013a. Disponível em: <http://g1.globo.com/goias/noticia/2013/05/piloto-de-aviao-agricola-queintoxicou-varias-pessoas-em-escola-esta-preso.html>. Acesso em: 12 dez. 2013.

20. Tarcísio T. Avião pulveriza agrotóxico "sobre” alunos em escola. Tribuna do Sudoeste, Rio Verde: Tribuna do Planalto; n. 407, pp. 1 e 4, 5 a 11 de maio de 2013a. p. 4.

21. Tv Anhanguera. Aluno grava sobrevoo de avião em escola atingida por veneno, em GO. Globo; 06 maio 2013c. Disponível em: 〈http://g1.globo.com/goias/noticia/2013/05/aluno-grava-sobrevoo-de-aviaoem-escola-atingida-por-veneno-em-go.html>.Acesso em: 12 dez. 2013.

22. Ação Civil Pública. Justiça Federal - Tribunal Regional Federal da $1^{a}$ Região. 1210600 Agrotóxicos - Meio Ambiente - Direito Administrativo e outras matérias do Direito Público. Ação Civil Pública com pedido de liminar n.0002437-59.2013.4.01.3503. Ministério Público Federal e União Federal, Estado de Goiás e Município de Rio Verde-GO. Vara única de Rio Verde-GO. Processo físico em curso, autuado em 25 de outubro de 2013. p. 133.

23. Tarcísio T. Avião pulveriza agrotóxico "sobre” alunos em escola. Tribuna do Sudoeste, Rio Verde: Tribuna do Planalto; n. 407, pp. 1 e 4, 5 a 11 de maio de 2013a.

24. Tv Anhanguera. Piloto de avião agrícola que intoxicou várias pessoas em escola está preso. Globo; 03 maio 2013a. Disponível em: <http://g1.globo.com/goias/noticia/2013/05/piloto-deaviao-agricola-que-intoxicou-varias-pessoas-em-escola-esta-preso.html>. Acesso em: 12 dez. 2013.

25. Ministério Público Estadual. $8^{\text {a }}$ Promotoria de Justiça da Comarca de Rio Verde, Ministério Público do Estado de Goiás. Autos extrajudiciais n. 201300227199. Procedimento administrativo. Medidas de proteção: envolvido(s) alunos (vítimas) e outros, de 04 de junho de 2013. p. 28-40.

26. Tv Anhanguera. Aluno grava sobrevoo de avião em escola atingida por veneno, em GO. Globo; 06 maio 2013c. Disponível em: <http://g1.globo.com/goias/noticia/2013/05/aluno-gravasobrevoo-de-aviao-em-escola-atingida-por-veneno-em-go.html>. Acesso em: 12 dez. 2013. 
27. Tarcísio T. Aerotex: responsáveis são liberados. Tribuna do Sudoeste, Rio Verde: Tribuna do Planalto; n. 408, p. 3, 12 a 18 de maio de 2013b.

28. Tarcísio T. Aerotex: responsáveis são liberados. Tribuna do Sudoeste, Rio Verde: Tribuna do Planalto; n. 408, p. 3, 12 a 18 de maio de 2013b. p. 3.

29. Tarcísio T. Aerotex: responsáveis são liberados. Tribuna do Sudoeste, Rio Verde: Tribuna do Planalto; n. 408, p. 3, 12 a 18 de maio de 2013b. p. 3.

30. Tv Anhanguera. Aluno grava sobrevoo de avião em escola atingida por veneno, em GO. Globo; 06 maio 2013c. Disponível em: <http:/g1.globo.com/goias/noticia/2013/05/aluno-gravasobrevoo-de-aviao-em-escola-atingida-por-veneno-em-go.html>. Acesso em: 12 dez. 2013.

31. Tv Anhanguera.Técnico é multado por indicar uso do agrotóxico que intoxicou alunos. Globo; 07 maio 2013d. Disponível em: <http://g1.globo.com/goias/noticia/2013/05/tecnico-emultado-por-indicar-uso-do-agrotoxico-que-intoxicou-alunos.html>. Acesso em: 12 dez. 2013.

32. Tv Anhanguera. Técnico é multado por indicar uso do agrotóxico que intoxicou alunos. Globo; 07 maio 2013d. Disponível em: <http://g1.globo.com/goias/noticia/2013/05/tecnico-emultado-por-indicar-uso-do-agrotoxico-que-intoxicou-alunos.html > . Acesso em: 12 dez. 2013.

33. Tarcísio T. Aerotex: responsáveis são liberados. Tribuna do Sudoeste, Rio Verde: Tribuna do Planalto; n. 408, p. 3, 12 a 18 de maio de 2013b.

34. Guimarães G. MP quer assistência a estudantes expostos a agrotóxico. Tribuna do Sudoeste, Rio Verde: Tribuna do Planalto; n. 408, p. 2 e 6, 30 de junho a 6 de julho de 2013a.

35. Guimarães G. MP quer assistência a estudantes expostos a agrotóxico. Tribuna do Sudoeste, Rio Verde: Tribuna do Planalto; n. 408, p. 2 e 6, 30 de junho a 6 de julho de 2013a. p. 6.

36. Guimarães G. MP quer assistência a estudantes expostos a agrotóxico. Tribuna do Sudoeste, Rio Verde: Tribuna do Planalto; n. 408, p. 2 e 6, 30 de junho a 6 de julho de 2013a. p. 6.

37. Tv Anhanguera. Alunos intoxicados com veneno de avião agrícola voltam ao hospital. Globo, 23 maio 2013e. Disponível em: <http://g1.globo.com/goias/noticia/2013/05/alunos-intoxicadoscom-veneno-de-aviao-agricola-voltam-ao-hospital.html>. Acesso em: 12 dez. 2013.

38. Mali T. Envenenados. Galileu: Editora Globo; n. 266, p. 46-59, set. 2013. ISSN 1415-9856. p. 50 .

39. Tv Anhanguera. Escola atingida por veneno agrícola é depredada, em Rio Verde, GO. Globo; 01 jul. 2013f. Disponível em: < http://g1.globo.com/goias/noticia/2013/07/escola-atingidapor-veneno-agricola-e-depredada-em-rio-verde-go.html>. Acesso em: 12 dez. 2013. 
40. Guimarães G. Debate sobre pulverização. Tribuna do Sudoeste, Rio Verde: Tribuna do Planalto; n. 422, p. 2, 18 a 24 de agosto de 2013b. p. 2.

41. Guimarães G. Simpósio promove debate científico sobre agrotóxicos. Tribuna do Sudoeste, Rio Verde: Tribuna do Planalto; n. 428, p. 6, 29 de setembro a 5 de outubro de 2013c. p. 6.

42. Guimarães G. Simpósio promove debate científico sobre agrotóxicos. Tribuna do Sudoeste, Rio Verde: Tribuna do Planalto; n. 428, p. 6, 29 de setembro a 5 de outubro de 2013c. p. 6.

43. Guimarães G. Simpósio promove debate científico sobre agrotóxicos. Tribuna do Sudoeste, Rio Verde: Tribuna do Planalto; n. 428, p. 6, 29 de setembro a 5 de outubro de 2013c. p. 6.

44. Guimarães G. Uso de agrotóxicos. Tribuna do Sudoeste, Rio Verde: Tribuna do Planalto; n. 432 , p. 2, 27 de outubro a 2 de novembro de 2013d. p. 2.

45. Guimarães G. Audiência pública debate contaminação por agrotóxicos. Tribuna do Sudoeste, Rio Verde: Tribuna do Planalto; n. 433, p. 1 e 6, 3 a 9 de novembro de 2013e. p. 1.

46. Brasil. Instrução normativa n. 2, de 3 de janeiro de 2008. Ministério da Agricultura, Pecuária e Abastecimento. Disponível em: <http://www.agricultura.gov.br/arq editor/file/ Agrot $\%$ C3\%B3xicos/IN2.pdf>. Acesso em: 7 abr. 2014.

47. Guimarães G. Audiência pública debate contaminação por agrotóxicos. Tribuna do Sudoeste, Rio Verde: Tribuna do Planalto; n. 433, p. 1 e 6, 3 a 9 de novembro de 2013e. p. 6.

48. Santos BS. A crítica da razão indolente: contra o desperdício da experiência. 8. ed. v. 1. São Paulo: Cortez; 2011. p. 266-267.

49. Ministério Público Estadual. $8^{\text {a }}$ Promotoria de Justiça da Comarca de Rio Verde, Ministério Público do Estado de Goiás. Autos extrajudiciais n. 201300227199. Procedimento administrativo. Medidas de proteção: envolvido(s) alunos (vítimas) e outros, de 04 de junho de 2013. p. 23-24.

50. Ministério Público Estadual. $8^{\text {a }}$ Promotoria de Justiça da Comarca de Rio Verde, Ministério Público do Estado de Goiás. Autos extrajudiciais n. 201300227199. Procedimento administrativo. Medidas de proteção: envolvido(s) alunos (vítimas) e outros, de 04 de junho de 2013. p. 28-40.

51. Ministério Público Estadual. $8^{\text {a }}$ Promotoria de Justiça da Comarca de Rio Verde, Ministério Público do Estado de Goiás. Autos extrajudiciais n. 201300227199. Procedimento administrativo. Medidas de proteção: envolvido(s) alunos (vítimas) e outros, de 04 de junho de 2013. p. 52-55.

52. Mali T. Envenenados. Galileu: Editora Globo; n. 266, p. 46-59, set. 2013. ISSN 1415-9856. p. 59. 
53. Reis AT, Batista AF (org.). Ensaios sobre a questão agrária. São Paulo: Outras expressões; 2013. p. 28.

54. Santos BS. A crítica da razão indolente: contra o desperdício da experiência. 8. ed. v. 1. São Paulo: Cortez; 2011. p. 27-28.

55. Teixeira ACA, Marinho AMCP, Ellery AEL, et al. Conceito, olhares e primeiras aproximações sobre o problema em estudo. In: Rigotto R (org.). Agrotóxicos, trabalho e saúde: vulnerabilidade e resistência no contexto da modernização agrícola no Baixo Jaguaribe/CE. Fortaleza: Edições UFC, co-edição com a Expressão Popular; 2011. p. 59.

56. Bogo A. Identidade e luta de classes. 2. ed. São Paulo: Expressão Popular, 2010.

57. Braga LQV, Silva MLV, Feitosa MP. Com a palavra, os que lutam: os movimentos de resistência das comunidade do Baixo Jaguaribe em defesa da terra, do trabalho e de modos de vida. In: Rigotto R (org.). Agrotóxicos, trabalho e saúde: vulnerabilidade e resistência no contexto da modernização agrícola no Baixo Jaguaribe/CE. Fortaleza: Edições UFC, co-edição com a Expressão Popular; 2011. p. 475.

58. Rosa IF, Pessoa VM, Rigotto RM. Introdução: agrotóxicos, saúde humana e os caminhos do estudo epidemiológico. In: Rigotto R (org.). Agrotóxicos, trabalho e saúde: vulnerabilidade e resistência no contexto da modernização agrícola no Baixo Jaguaribe/CE. Fortaleza: Edições UFC, co-edição com a Expressão Popular; 2011. p. 218.

59. Rosa IF, Pessoa VM, Rigotto RM. Introdução: agrotóxicos, saúde humana e os caminhos do estudo epidemiológico. In: Rigotto R (org.). Agrotóxicos, trabalho e saúde: vulnerabilidade e resistência no contexto da modernização agrícola no Baixo Jaguaribe/CE. Fortaleza: Edições UFC, co-edição com a Expressão Popular; 2011. p. 226.

60. Sampaio JLF, Lima AEF, Freitas BMC. As bases geo-históricas do Baixo Jaguaribe. In: Rigotto R (org.). Agrotóxicos, trabalho e saúde: vulnerabilidade e resistência no contexto da modernização agrícola no Baixo Jaguaribe/CE. Fortaleza: Edições UFC, co-edição com a Expressão Popular; 2011. p. 125.

61. Marinho AMCP, Carneiro FF, Almeida VE. Dimensão socioambiental em área de agronegócio: a complexa teia de riscos, incertezas e vulnerabilidades. In: Rigotto R (org.). Agrotóxicos, trabalho e saúde: vulnerabilidade e resistência no contexto da modernização agrícola no Baixo Jaguaribe/ CE. Fortaleza: Edições UFC, co-edição com a Expressão Popular; 2011. p. 170.

62. Marinho AMCP, Carneiro FF, Almeida VE. Dimensão socioambiental em área de agronegócio: a complexa teia de riscos, incertezas e vulnerabilidades. In: Rigotto R (org.). Agrotóxicos, trabalho e saúde: vulnerabilidade e resistência no contexto da modernização agrícola no Baixo Jaguaribe/ 
$132 / /$

CE. Fortaleza: Edições UFC, co-edição com a Expressão Popular; 2011. p. 210.

63. Rosa IF, Pessoa VM, Rigotto RM. Introdução: agrotóxicos, saúde humana e os caminhos do estudo epidemiológico. In: Rigotto R (org.). Agrotóxicos, trabalho e saúde: vulnerabilidade e resistência no contexto da modernização agrícola no Baixo Jaguaribe/CE. Fortaleza: Edições UFC, co-edição com a Expressão Popular; 2011. p. 240.

Artigo apresentado em 07/04/14

Artigo aprovado em 18/06/14

Artigo publicado no sistema em 29/06/14 